\title{
CHALLENGES OF GLOBALIZATION: HOW BANGLADESH CAN ADAPT ITSELF TO REAP THE BEST BENEFITS IN THE $21^{\text {sT }}$ CENTURY
}

\author{
Lt Colonel Sharif Md Abul Hussain
}

Dir Planning and Development, Bangladesh University of Professionals, E-mail: hussain2682@gmail.com

\begin{abstract}
The study investigates specific information regarding the challenges of globalization faced by Bangladesh and how it should prepare itself to coup with the challenges. The result suggest that Bangladesh is not in comfort in coping with the winds of globalization, as it has less access to and use of different opportunities living at the margin in the hierarchies of global order with low technological base, poor infrastructures and governance in most arenas. The study also suggest that Bangladesh needs to be engaged with all its development partners in a healthy and constructive process of interaction on stabilization, reform programme and other critical issues like national capacity building, competitiveness, political stability, cross border terrorism, arms and drug trafficking, climate change and environmental degradation. The policy implication is that various economic policy orientation and utilization of resources should be as such that they can supplement economic growth in a sustainable manner and create avenues for employment.
\end{abstract}

KEY Words: Benefit, Environment, Globalization, Governance, Infrastructure, Poverty, Population, Policy, Political stability, Resource

\subsection{INTRODUCTION}

Globalization is a process of expanding trade and commerce creating borderless market all over the world. Some view it to be the conquest of one by other increasing inequality between nations. Others view it to be benefiting for world economic development and - also inevitable and irreversible.

Bangladesh is exposed to pressure from two major sources in order to bring about changes in domestic governance in the direction of globalization. Primarily it is coming from International Donor Community (IDC), previously through 'Structural Adjustment Programmes' (SAPs) and 'Stabilization Programmes' and currently as a general condition of aid from all external sources, governments to agencies. The transformation of global environment towards market, democracy and individuals with understanding principles of competitiveness is pushing Bangladesh to accept the rules and norms of globalization. Donors are using the concept of "Good Governance" and "Globalization" as part of their global agenda.

The economic benefits of globalization - faster growth, cheaper imports, greater export and investment, and new technologies that the world has enjoyed in recent years are too easily taken for granted. Despite all the gains that globalization brings, it has also created losses - mostly developing countries like Bangladesh whose relative deprivation and marginalization, have led to the perception that globalization is not also irreversible in the aftermath of the failure of the WTO conference, there is a stronger-than-ever perception of the need for deeper exploration of social and political dimensions of globalization that in order to move forward on the path of free trade and higher economic growth, issues of equity and fairness both within and among nations should be addressed. In fact, the lack of effective governance at national level has prevented the benefits of globalization to reach to the poor peoples of Bangladesh. The impact of globalization, its form, extent and multiple linkages are, therefore, very important in understanding how the process of globalization will unfold in the future, and how Bangladesh will work out its political, social and cultural costs as it tries to reap its benefits in the new millennium.

The significance of globalization differs for individuals, groups and countries. The impact of various global flows varies depending on the stage of economic development of a country, its access to technology, strength of its state and democratic institutions, and cultural characteristics. In other words, the heart of the matter is the "Differential 
Access" to power, where power is conceptualized as the capacity to transform material circumstances - whether economic, political or social and to achieve goals based on the mobilization of resources, the creation of the rule system, and the control of infrastructures and institutions. The differential, unequal, and uneven access to the dominant organizations, institutions and processes of the new global order has, therefore, come under increasing attack.

Like many other developing countries, Bangladesh is not in a comfortable position to cope up with the winds of globalization, as it has less access to and use of different opportunities, living at the margin in the hierarchies of global order with low technological base and weak industrial infrastructure. The impact of globalization, its form, extent and multiple linkages are, therefore, very important in understanding how the process of globalization will unfold in future, and how Bangladesh will work out its political, social and cultural costs as it tries to reap its benefits out of it.

This study is descriptive in nature. It aims to find out specific information regarding the challenges of globalization faced by Bangladesh in different sector. The scope of the paper has been kept limited in determining the ways to reap benefits of globalization and a recommended approach to address the challenges faced by Bangladesh in 21 st century.

\subsection{AIM}

The aim of this paper is to study the challenges of globalization faced by Bangladesh to determine the ways to reap the benefit in the $21^{\text {st }}$ century

\subsection{The Challenges of Globalization FACED BY BANGLADESH}

\subsection{GeneraL}

Technology has made the whole world a global family. Sharing of culture, behavior and experiences have overcome the territorial boundaries. The challenges faced by Bangladesh in terms of globalization in social, political, cultural, economic fields are enumerated in the subsequent paragraphs.

\subsection{THE STATE OF ECONOMY}

The absence of law and order, the rampage by terrorists, the sway of fundamental fanaticism, the desperate situation of education, the crowding by the masses of unemployed people and the misery of millions of poor depict a picture of terrifying hopelessness. The country is singularly resource poor. It does not have enough mineral or natural resources from which income can be easily generated to use for the welfare of its vast masses. The miserable state of human resources is a cause for serious concern. Looking at the deprivation level in the education, nutrition, health and shelter and judging the poverty and unemployment scenario, many observers note the inevitability of the state of nature in Bangladesh.

\subsection{LACK OF QUALiTy EdUCATION}

The learning materials are pedantic and rather formal and do not impart practical knowledge to the students. The teaching methods are archaic and irrelevant. The overall interest in education is limited because female education was not emphasized in the past.

\subsection{Low Agricultural Production}

Unbalanced Application of chemical fertilizers can be attributed for degrading soil fertility. Croplands are also depleting fast. The amount of land lost for urbanization every year is not supplemented by the increased productivity.

\subsection{THE ENVIRONMENTAL REALITY}

The environment of Bangladesh is extremely fragile. The people-resource ratio is very adverse. The pressure of population on the natural resources of the country is very great and on the top of it are constraints of poverty and illiteracy. The needs of poor do not allow for conservation of the environment and lack of education stands in the way of ecological consciousness.

\subsection{The Problems of Governance}

The problems are three levels; firstly, in the political processes which gives the country its government. Secondly, in the structure of the government this determines the various layers of its operation. Finally, in the administrative structure and practices which execute the programmes of the government.

\subsection{Poverty IN BangladeSh}

Bangladesh has been experiencing with a mix of macroeconomic, sectoral, institutional and target oriented strategies to combat the problems of poverty. 


\subsection{The Weakness in Population Planning Programme}

The demand for family planning services is very strong and facilities are not sufficient to meet this demand. The allocation of resources for health and family planning sector is very meager. The total public expenditure on health and population planning is only 0.9 percent of Gross Domestic Product (GDP).

\subsection{CYNICISM AND DISREGARDS}

Cynicism and disregard for moral and legal principles are now reigning among a large segment of political activists and general mass and are often sheltered by political parties. The ubiquitous nature of politics has already intensified social insecurity - the organized crime, pervasive violence, lack of confidence in police and corruption in public institutions have undermined the ethics of citizenship and the image of the nation. However, recent steps taken by the present government to improve the law and order situation by reorganizing the law enforcing agencies have brought some positive results and earned good reputation of the international community.

\subsection{LACK OF SUSTAINING DEMOCRATIC GOVERNANCE}

In Bangladesh, political leadership has been falling again and again in sustaining democratic governance. To ensure overall development of the country and to face the challenges of globalization, the present democratic process of governance of Bangladesh needs to be upheld at any cost.

\subsection{FOREIGN DIRECT INVESTMENT}

Bangladesh has been trying to attract foreign investment but so far no significant level of investment has been forthcoming due to a number of reasons, political instability being the main. Other reasons are listed below:

a. The linkage between prosperity, choice and freedom creates more tensions and challenges. The challenge before Bangladesh is how to attain this goal in an environment where major economic decisions affecting national life are often determined by the international markets.

b. The basic challenge facing Bangladesh is to comprehend the nature of changes taking place in the international economy and to deal with them through creating conditions and institutions necessary for coping with a dynamic environment.

c. The main objectives of Bangladesh's foreign policy viz upholding its sovereignty, cultural identity, ideologies are challenged by the forces of globalization.

d. In the environment sector Bangladesh faces a number of challenges concerning the control of the flow of Ganges water by India, desertification, deforestation, global warming and so on.

\subsection{GARMENTS SECTOR}

It is not easy for Bangladesh to specialize in manufactured exports. Having low wage costs can hardly compensate for its lack of marketing skill, infrastructure and poor overall investment climate. Moreover, the high degree of dependence of domestic industries on imported raw materials and industrial inputs makes it difficult for Bangladesh to satisfy the so called "Rules of Origin" in getting preferential access for its exports in the markets of the developed countries. Most of Bangladesh's garments exports are not eligible for tariff concessions given under the Generalized System of Preference (GSP) in the EU market. The removal of the Multi Fiber Agreement (MFA) quotas now threatens to increase competition in the global garment industry and thus limits Bangladesh's growth. More than 5.9 million people directly or indirectly (Directly 3.4 and Indirectly 2.5) involved with this sector which provides 77 percent of total export earning of the country is threatened by recent workers unrest. Among many minimum wage is the important one such unrest in the garments sector.

\subsection{Country SECURITY AND ForeIGN Policies.}

In the era of globalization, Bangladesh, like other developing countries, is confronted with threats emanating from both external and internal sources: terrorism, drug trafficking, circulation of light weapons, poverty, political instability, environmental degradation and so on. The main purpose of Bangladesh's foreign policy in the present era should be minimizing the degree of vulnerabilities and reducing threats to its security, as well as possessing the ability to shape its 
security environment through an effective and realistic assessment of its national interest, and the promotion thereof through pragmatic and active diplomacy.

\subsection{WAYs TO REAP BEST BENEFIT IN THE 21 $^{\text {ST }}$ CENTURY}

\subsection{GeneraL}

The globalization process offers both opportunities and poses challenge for Bangladesh. It has both positive as well as negative impacts. The positive impacts include influence on parliamentary democracy and adult franchise, a global outlook and modern mindset of the people, the positive effect on education, environment and women emancipation, access to IT, the entrance into global trade, marketing and joint-venture entrepreneurship and the availability of high quality and low cost products. The negative impacts include the downfall of local industries and products and competitiveness resulting in local unemployment, the threats to the survival of culture, community norms, ethics and values, the widening of the gap between the rich and poor; and the foreign dominance and dependency on investors. Bangladesh, although poor in most respect, is not entirely without resources. It has manpower (cheap labour), water resources and mineral resources (coal, gas and oil), if mobilized effectively, its vast but homogeneous and resilient population can take advantage of the information technology that is now available and in the process create a pool of skilled labour force. The per capita low-income in Bangladesh can be attributed to the workers inadequate training, capital and technology. The liberal international trade has led to an increase in the level of employment. Therefore, there is an urgent need for Bangladesh to conduct its economic diplomacy with vigor and vision. The ways to reap benefit from different sectors are enumerated in the subsequent paragraphs.

\subsection{ForeIGN PoLICY}

The foreign policy of Bangladesh should focus to broaden the scope for prosperity through the creation of a modern and efficient economy. It is mandatory for Bangladesh to make diplomatic efforts to make it possible for the Bangladeshi workers to work in other countries where there re better opportunities. In this era of competition, Bangladesh will not necessarily get what it thinks to deserve but only what it can negotiate. If the issue is not negotiated through legal means, it is not impossible that labour would flow out of the country illegally.

\subsection{FREE FLOW OF INFORMATION}

Bangladesh needs to take advantage of the opportunities that globalization offers through the free flow of information and the use of English as an international language. This would help produce a better-trained workforce capable of competing at the international level. It is well know that productivity is linked to skills and knowledge.

\subsection{ACCESS TO MARKETS}

Bangladesh has to negotiate preferential access to the markets of the western developed countries, as well as those of India and China, huge trade gap in the bilateral trade relations has to be redressed. In the era of competition, Bangladesh will not necessarily get what it thinks to deserve but only what it can negotiate.

\subsection{Poverty Alleviation}

Poverty is a source of insecurity for Bangladesh. But whether globalization as such would alleviate poverty is debatable. However, the alleviation of poverty depends on the capacity of Bangladesh to mobilize resources in an optimum way. There is something that can be achieved if there is political stability inside the country. A truly stable democratic system can function only when there are robust democratic institutions and a vibrant civil society. Inability to achieve political stability would not only result in our failure to take advantage of the positive aspects of globalization but our foreign and economic policy agenda would be set outside the country.

\subsection{GOOD GOVERNANCE}

Openness in government operations should be the rule rather than the expectations. This has two implications for macro-economic performance. Firstly, it will expedite economic decisions as it will follow an open process and will not be turned in to deal making as it usually is. Secondly, it will secure the commitment of the nation to any programme of action. The measures for open government will be in many areas but most importantly it will mean parliamentary consideration of important issues and many topics, which are now considered secret. 


\subsection{Sustainable Democracy}

Certain basic issues such as economic policy framework, foreign policy and international relations, specially water sharing with Nepal and India, transit facility with India, development of growth quadrangle, asset settlement with Pakistan, reform in important economic sectors, public service restructuring and reforms and local government structure and reorganization should be discussed in the parliament. Public representatives should be allowed to finalize policies after ascertaining the views of the civil society through hearings and dialogues. To have constructive discussion in the parliament political parties should be more accommodative in accepting and criticizing others.

\subsection{Rule of LAW}

The broad category of issues relating to the rule of law is to be reorganized. This covers human rights, law and order situation and the judicial system of the country. The rule of law is not simply a sine-qua-non for a civilized society but also a precondition for investment growth and economic vitality.

\subsection{FunCtional AREA IMPROVEMENTS}

Political reorganization by itself cannot deliver modernization. For modernization and development both political and administrative reforms are equally important for any country. In the field of administration following areas may be addressed:

\section{a. Policy Making Function.}

Policymaking functions must be strengthened. One of the major weaknesses in Bangladesh administration is the policy making and policy planning capacity. The incompetence of the democratic governments, which is so obvious, is partly because of the institutional weakness of policy planning apparatus. This has to be rectified by the practice of the democracy at all levels and induction of political appointees at higher levels of government.

\section{b. Poverty Alleviation Strategy:}

Poverty alleviation is both a social and economic imperative in Bangladesh. The deprivation of the vast masses is socially unsustainable and political stability and social peace demand poverty eradication. Bangladesh can be a vast market only when its people are not too poor and have enough purchasing power.

\section{c. Population Planning.}

Another sector warranting urgent attention is population planning. Unless population growth is arrested, poverty reduction will be a distant dream. Population planning is not only family planning but it covers matters relating to health care and sanitation is particular infant mortality care are of serious significance.

\section{d. INFRASTRUCTURE DEVELOPMENT.}

Infrastructure investment deserves priority attention because of its potential for employment generation. Institutional strategies can be pro-poor on the one hand and on the other indifferent to poverty problem if not adverse outright. Institutional reforms aiming at empowering the poor are fundamental to poverty eradication. The various strategic can be in the areas of labour policy, land and tenurial laws, credit system, small and medium enterprise (SME) development and above all restructuring of local governments. The promoters and organizers of poverty programmes must form coalitions or groups of the poor and at the same time legal and regulatory support should be provided by the government. In Bangladesh measures should be taken for the registration of the rights of sharecroppers with a view to providing good support to groups of poor people so that they can put in their best efforts to improve their economic conditions. Such practices are the empowerment of the poor. Above all mass education is the strongest empowering instrument; it is indeed the great leveler.

\section{WOMEN EMPOWERMENT.}

It is also important that legal provisions are made for affirmative action for the poor and especially women. Representation of women in political and social forum must be ensured empowering them, as they are the most discriminated and deprived class of the society.

\section{f. Employment Creation.}

Targeted programmes are another kind of interventions that can have salutary impact on poverty amelioration. In order to enhance employment creation activities Bangladesh should launch targeted programmes such as package programme for under developed or backward areas or communities. Programmes for income generating activities encompassing matters like training, credit and marketing, schemes of transfer payments to help the poor and the disadvantaged needs to be enhanced. Bangladesh needs 
opportunities for employment and for income generating activities. The government and the NGOS working in Bangladesh should undertake the two programmes widely for income generation poor people can be provided with some credit in the form of working capital for whatever they are used do doing.

\section{g. Food Production.}

Food production can be increased under the existing smallholding that we have in the country. Problem lies in the input output prices for the agricultural sector. Growers have no control over any of them. Paddy, potato and vegetable prices go down sharply at harvesting time, as small growers cannot hold them. Farmers mostly sell their output forward to moneylenders and middlemen, as they cannot finance purchase of inputs, seed fertilizer and water from their savings that never accrue to them. The scaling up of MFIs should cover crop production and storage. This will have tremendous impact on the income of farmers and they will in turn invest and consume more of their goods and services.

\section{h. Strengthening Other Sectors.}

Bangladesh should utilize revealed strengths in Ready Made Garments (RMGs), NGO-MFIs and give incentives to the farmers to produce more. We must try to reduce our weaknesses in delivery of certain public services such as education and health, law and order.

\section{Qualitative Education.}

Enrolling more girls to school and colleges is good provided they obtain certain skills in language and quantitative analysis in the least. Currently very little is learnt and the system loss in failure to public examination is huge. Education must be an essential element in poverty reduction strategy.

\subsection{InVestment Climate.}

In Bangladesh, high cost sour investment climate. Bangladesh is not the cheapest country in Asia as per as the investment related cost is concerned. The cost of water in Dhaka (US\$ 0.32 oer cubic meter) is higher than shenzen (US\$ 0.23), Sanghai (US\$ 0.15) and Hanoi (US\$). The monthly basic charge for mobile phones, price of gasoline and cost of passenger car in Bangladesh is also higher than average cost of those items in Asia. The wage of workers in Bangladesh is the second cheapest in Asia. But a foreign investor considers not only the wage of workers but also the cost of electricity, water, transport, telecommunication, taxation and so on for an overall evaluation before he can make the decision.

\subsection{FOREIGN INVESTMENT.}

Foreign investment is definitely essential for economic development of Bangladesh. For attracting foreign investment to come to Bangladesh without going to China, Vietnam or to other Asian countries, it is essential to make the investment climate much more attractive than that prevailing in those countries. Bangladesh can take up the following four measures to make the investment climate attractive:

a. Firstly, the costs comparatively higher than other countries should be lowered, as an enterprise will always invest in a country where the return of investment is high.

b. The second suggestion is for continuity of policy matter. An investment is always made in long-term considerations and therefore, it is never desirable that a policy is changed thoughtlessly or a project in progress is suddenly cancelled due to policy change, especially due to change of the power from one political party to another.

c. The third one is improvement of infrastructure facilities. For example, ensuring a steady supply of electricity, gas at a reduced cost.

d. The fourth recommendation is for instituting fairness and speed in approvals given by different government departments.

\subsection{Framing OF DeVElopment Strategy.}

Trade policy should not form the basis of an overall growth and development strategy in the policy of Bangladesh. The development strategy must be constructed around country specific characteristics in a manner that efficaciously manages trade associated with globalization. This does not necessarily dictate greater economic integration through increased trade and capital flows. Two shining example of countries that benefited from conscious efforts are Chile (Following the stabilization plan in the 1970s) and Malaysia (following the Asian Financial Crisis). Globalization is an inescapable reality that offers choices for national economic policies. Hence, the policies of Bangladesh must be made consistent within a framework of principles that appreciate individual country characteristics. If policy 
makers are able to maintain there perspectives, the best of times are indeed ahead of us.

\subsection{Globalization AND NATIONAL Culture.}

Globalization is a process that involves free and unrestricted interactions between nations of the world largely as a result of deregulation and improved communication and media channels/ The fear that globalization will affect our culture adversely by exposing it to foreign and in many cases wholesome influences is not justified. Our traditional values, beliefs and attitudes are not newly acquired possessions and hence, not so delicate as to be corrupted from exposure to foreign influences in he wake of globalization. The process of globalization can bring before the whole world the genuineness, the natural simplicity and the element of humanity that are treated as the fundamental features of our culture. Globalization can also enable us to benefit form the advanced refined cultures of other nations of the world. Something that is good and authentic has nothing fear for its existence and survival. The intrusion of foreign culture should not be any threat to our cultural identity. Because, firstly, there is solidity in it and secondly, it has stood the test of time. We are in possession of a type of culture that has the inherent strength, refinement and robustness to withstand the stand however stupendous they might be.

\subsection{INTEGRATION OF NATIONAL ECONOMY.}

The increasing integration of national economies into global markets if properly carried out, certainly promises to alter dramatically the volume and character of the gain of Bangladesh from international trade and resources flow in to the economy of Bangladesh. Besides, the increasing size, competitiveness and diffusion of financial markets have the potential to draw the economy of Bangladesh into the global economic mainstream if Bangladesh can create the necessary conditions and also fully exploit the comparative advantage of Bangladesh in specific areas. The phenomenal success of the RMG sector of Bangladesh is a case.

\subsection{How to AdDress Challenges GLOBALIZATION $\quad-\quad$ SOME RECOMMENDATIONS}

Globalization is an economic parallel to international isolation in the form of universal rule of the market, free trade and global flow of capital through spread of information technology. Bangladesh is not in comfort in coping with the winds of globalization, as it has less access to and use of different opportunities living at the margin in the hierarchies of global order with low technological base and poor governance in most arenas. I would like to suggest some ways and mean to address global crises confronting Bangladesh.

\subsection{NEED FOR GOOD GOVERNANCE}

Bangladesh needs improvement on the normative structural and substantive aspects of policy and political framework. The normative political discourse and ideological question of culture needs to be linked with the issue of political leadership as a factor in regime legitimization.

The entire civil society comprising businessmen, journalist, professionals and intellectuals should mobilize public opinion towards creating the must crucial broad consensus on vital national issues and resolving power conflicts in a peaceful manner. There should be some political reforms so as to make individual politicians or parties responsible for their policies and actions whether in power or out of power.

The good governance hinges mainly on how the law is used by the state as an instrument of public policy that holds moral conduct that would be a matter of rule following and moral relationship to consist of duties and rights determined by rules. The globalization process should be brought to ensure that such moral conduct is reflected in the legal framework of governance. In fact, economic globalization will be fruitless without political liberalization and reduction of social marginalization.

The rule of low is not simply a sine-qua-non for a civilized society but also a pre-condition for investment growth and economic reality. There should be law and order for investment to take place and production to multiply. Participatory governance in Bangladesh should serve to enhance the voice of the poor, thus helping to improve the quality of public health, education and social services delivery.

\subsection{NEED FOR IMAGE BUILDING}

Bangladesh is misrepresented to the world as a country of natural calamity, violence, and intolerance and population boom. The process of globalization where interaction will be more will 
create ample scope to let know the real picture of Bangladesh and its people. The main role in this connection should be played by the media and Foreign Service department in different countries in picturing a good image of the country.

\subsection{BENEFITING FROM ENGLISH LANGUAGE}

The process of globalization obviously requires a common language for International Communication. For many different reasons, English has achieved the pristine of being that language. As a result it has crossed the national benders to reach people who speak other languages. As more and more people speak English, more and more varieties have emerged which are strongly influenced by the pronunciation, grammar and idioms of respective mother tongues. World English has now moved away from the control of its native speakers. In order to enhance 'mutual intelligibility among users of the English language, English Language training should be designed properly to promote productivity.

\subsection{ENHANCING THE MODERN TeChNOLOGICAL BASE}

Globalization is now largely based on a strong technological foundation. The electronic transfer of information via Internet has now created an instantaneous and interconnected world of information resulting in a 24 hour trading network. The advancement in information and technology will help disseminate knowledge in the field of study and technology. Globalization is now only what technology makes possible.

\subsection{ENHANCING THE CAPACITY FOR WORK IN BANGLADESH}

Bangladesh will have to take revolutionary steps for expansion of the capacity for work for its people. The following strategy of energy development may be adopted:

a. Demand and supply of energy should be planned on the basis of discrete areas into which the country should be divided.

b. For electric power generation and distribution, waiting applicants for generation of power should be permitted to undertake a large number of projects. The monopoly of power Board in supply of power to customers should be broken. c. The policy on trading energy resources must be very pragmatic. Coordinated planning of energy development and supply should enjoy priority in Bangladesh. However, equally gigantic is the need for enhancement of the capacity for work for a huge number of people. If the problem is dealt with on a regional basis, the solution of the problem becomes manageable.

d. The over all investment in the energy sector in Bangladesh is quite low. A total of 1.5 to 1.75 percent of the GDP is the investment of the country on energy development and supply. For the rapid growth of energy sector, Which is an imperative of the highest order, the rate of investment must be accelerated to about 5 percent of GDP. For the discovery, exploration and development of energy resources, large and lumpy and long term investments and needed.

\subsection{Capitalizing The Excellence OF PROFESSIONALS :}

Globalization is the subject per excellence for the engineers. The engineers have all through played a significant rule; though never dominate one, in the globalization process. Engineers will have to join forces with biologists, chemists, meteorologists, economists, planners, political scientists, ethicist and community leaders in unprecedented ways to lead society on a sustainable path. They must play a much stronger role in the public policy process to provide the right incentives for industry and other to move on a sustainable path so that engineers can be supported and encouraged to design sustainable technology. The engineers of Bangladesh should accept the idea of globalization as an emerging and powerful global reality and to formulate strategies to manage it to minimize the adverse effects and maximize the gains form it.

\subsection{HuMAN RESOURCE DEVELOPMENT}

The lack of quality education and skilled teachers, poor educational infrastructure and outmoded syllabus are some major impediment to more successful basic education. For raising the standard of education, monitoring and supervision, Bangladesh can establish some sort of institutional framework to enable the private sector to take the lead in investing in the basic education sector. The government should exempt tax on donation in the education sector so that the private sector feels more encouraged to play a 
more proactive rote. For an industrial society of flourish, learning must receive the highest priority, a revolution must take place $\mathrm{i}$ freethinking and the spirit of enquiry must be all pervasive.

\subsection{InCReasing the Productivity in Agricultural Sector}

Unbalanced application of chemical fertilizers can be attributed for degrading soil fertility. Now the soaring process of TSP and MP act as a disincentive to applying balanced dozes of fertilizer. Croplands are also depleting fast and rice is grown on 75 percent of arable land, which does not augur well for other crops. Seizing the opportunity of globalization, newer technologies should be evolved so that per unit productivity sees a phenomenal growth. The wide gap between rice yields at breeders' plots and farmer's fields needs to be bridged.

\subsection{Creating a Congenial INVESTMENT CLIMATE}

For a dynamic investment climate, Bangladesh should confront the following pre conditions considered conducive for investment:

a. Primacy of political pluralism.

b. Establishment of the rule of law.

c. Dominant role for local government and community initiatives.

d. Rapid spread of education.

e. Widespread dynamism in agriculture sector.

f. The environment of an open and competitive economy.

\subsection{ATtracting The Direct Foreign INVESTMENT (DFI)}

In a country lake Bangladesh where local investors are shy, it is very difficult to attract foreign investors. Besides, many of the advantages sought by DFI are not readily available in Bangladesh. To cope with the situation, travel must be made free as transactions have recently been made so, energy supply must be efficient and reliable and the regulatory culture must be abandoned, financial and physical infrastructure must be made hospitable and an educated labour force should be created.

\subsection{Alleviation of Poverty}

The poverty problem in Bangladesh is extremely difficult. The only way to overcome this predicament is development of human resources at a rapid pace and acquisition of high-level skills. In order to create employment opportunities for its vast.labour pool and wealth that can be shared by the deprived there must be investment output growth. Social investment must grow to improve the quality of life and enhance the productivity of the human resources of Bangladesh. Local government should be strengthened for social investment, employment programme, environment protection and infrastructure development.

\subsection{CONCLUSION}

Like many other countries Bangladesh faces the challenges of globalization. It deserves mention that technically deficient developing and least developed countries are at a very disadvantageous position to reap the potential benefit from globalization. Bangladesh has to be engaged with all its development partners in a healthy and constructive process of interaction on our stabilization and reform programme and other critical issues. There are many developing countries that do not benefit from the opportunities offered by globalization. Therefore, Bangladesh should want an inclusive globalization form below and with a human face making consultative mechanisms more focused and effective at all key decision-making points.

The most pressing task before Bangladesh is to achieve political stability. As long as Bangladesh is domestically not in order, it would not be realistic to expect it to have a credible and effective foreign policy.

Bangladesh needs to deal with challenges like transnational economic and financial forces, crops border terrorism, arms and drug trafficking, climate change and environmental degradation through co-operation and coordinated efforts at both regional and international levels. The objective of Bangladesh foreign policy should be to minimize the degree of vulnerabilities and reduce threats to its security as well as possess the ability to shape its security environment though an effective and realistic assessment of its national interests and the promotion thereof through pragmatic and active diplomacy.

Globalization syndromes generate a major policy challenge for the people and government of Bangladesh. Neo institutionalism is a right kind of 
approach for Bangladesh, which takes in to consideration the critical issue of national capacity building and competitiveness. The pursuit of transnational integration and convergence will have to be associated with adequate domestic preparedness for competitiveness.

The various economic policy orientation and utilization of resources should be as such that they can supplement economic growth in a sustainable manner and create avenues for employment.

\section{REFERENCES}

[1] Baker, Dean et al, "Globalization and Progressive Economic Policy", Cambridge University Press, UK, 1998.

[2] Khan A R, "Globalization and Non-traditional Security in South Asia" Rgional Centre of Str4ategic Studies, Colombo, pp 88-273, 2001.

[3] Scholte, Jan Arta, "Globalization: A Critical Introduction”, Mac-Millan Press Ltd, London, 2000.

[4] Bazlul Haque and et el, "The Era of Globalization and Emerging Issue: Challenges and Plolicy Options for Bangladesh", Volume XIV, Number II, p 107 (Science Review), December, 1998.

[5] Nayyar, Deepak, 2000, 'Gloalization and Development Strategies', UNCTAD Discussion Paper $\mathrm{X}, 2 / \mathrm{OO}$.

[6] Nicholas Crafts, "Globalization and Growth in the Twentieth Century", IMF Working Paper, WP/00/44, Washington DC, April 2000.

[7] Centre for Policy Study, " Independent Review of Bangladesh Development", Volume II page 135, University Press Limited, 1991.

[8] Chowdhury, Toufic A, and Raihan, Ananya, “ Implications of WTO on the Banking and Financial sector of Bangladesh", (Unpublished research report). BIBM, Dhaka, 1999.

[9] Dr. Ataur Rahman, “ The Concept of Globalization", The Daily Star (Dhakja), January 29, 1999.

[10] M A Muhit, "Bangladesh in the twenty First Century" University Press Limited, p 112, 2003.

[11] Ruksana Kibria, "Globalization and Bangladesh's Security and Foreign Policies", Internet Eddition;2002.

[12] R Sohan and M Ahmed " Public Enterprise in and intermidiate Regime; A study in Political Economy of Bangladesh", BIDS, Dhaka, 2004.
[13] World Bank, " Private Capital Flows in Developing Countries", Oxford University Press, pp 913, 1997.

[14] "Globalization and Engineers of Developing Countries", The Daily Star, January 16, 2003.

[15] Rehman Sobhan, Interview with Sabir Mustafa, “ The Daily Star” March 3, 2002.

[16] "Some Effects of Globalization", The Bangladesh Observer, January 23, 2001.

[17] Asian Development Outlook 2001 - Part III Asia's Globalization Challenge - ADB org.htm.

[18] Centre for Plicy Dialogue " The Daily Star (Dhaka)", March 15, 2004.

[19] http://www.GlobalEnvision.org 